\title{
The Topological Reading of Ambiances in the Built Environment: The New Methodology for the Analysis of the Luminous Ambiance in the Museum Space
}

\author{
Selma Saraoui ${ }^{1, *}$, Azeddine Belakehal ${ }^{2}$, Abdelghani Attar ${ }^{3}$ and Amar Bennadji ${ }^{4}$ \\ ${ }^{1}$ MAA at the Department of Architecture, University of Bejaia, Algeria \\ ${ }^{2} \mathrm{Pr}$, Laboratory for Design and Modeling of Forms and Ambiences (LACOMOFA), the \\ Department of Architecture, University of Biskra, Algeria \\ ${ }^{3} \mathrm{MCB}$ at the Department of Architecture, University of Bejaia, Algeria \\ ${ }^{4}$ Dr, The Scott Sutherland School of Architecture and Built Environment, The Robert Gordon \\ University, UK
}

\begin{abstract}
Daylight is currently at the centre of discourse on architectural space. The definition of architectural space takes essence from Euclidean geometry related to metric dimensions. The present study is an attempt to shed light on topology which is a non-Euclidean geometry. It can support non-metric components of space such as light to define architectural space. A corpus of six European museums has been chosen to study the immaterial or material relationships between form and daylight, since light is an essential element for the success of the exhibition. It also seeks to highlight discontinuity reports, and to confirm their existence through their software visualizations Therefore, the current study has taken into account an analysis model based on the notions of "route" and "sequence". The contemporary architectural project focused on taking into account human postures, both physical and psychological, within the architectural space. The results obtained show that light can release other spatial features for the museum space that can be highlighted by visualization with sequential analysis.
\end{abstract}

\section{Introduction}

Architectural space is one of the most crucial concepts and can offer a varied palette of definitions. It can be defined as a space organized by the construction, which often refers to the architectural object. Others define it as a hollow space that has meaning through function

*Corresponding author: saraoui.selma@gmail.com 
and inner/outer relationship [01], or also as a three-dimensional space that includes man. This definition takes into account man's own internal space, which is often the space that surrounds us. [02]

Among other definitions that often appear in research work on architectural space, that of Jean Cousin [03] notes that the human body is surrounded by a bubble that constitutes its personal space. The latter is not only limited to the surface of the skin, but is also limited to the visual fields on spatial extensions (depending on what the human being sees around him). The definition of the architectural space presented by researchers is often an anthropological one. If we take architectural space outside its interaction with human beings, it becomes a mathematically geometric, three-dimensional space that has precise dimensions.

The evolution of theories on architectural space and its relationship to human experience, particularly those related to ambiances, has shown that there are two ways of studying space. A very rational way of studying it that excludes the human being, and focuses on the physical parameters of space called "quantitative", based on quantifiable measures and values of the environment. The second is related to the human being and his behaviour in space, and is based on the qualities of space.

The tools for representing space in our era do not only deal with geometric aspects, but also with the sensory aspects of architectural space. And so, we are witnessing the use of software that allows this new representation. This representation of space by software takes care of many aspects: dimensions to scale, climate files, context, orientations, materials, etc. These aspects make the representation very close to the reality of space. We are no longer talking about simple modelling, but rather about the visualization of architectural space.

The present research seeks to investigate the participation of the visualization of the lighting atmosphere, and the creation of a new definition of architectural space has become possible. The latter not only takes care of its geometric aspect, but also its sensory reality through the discontinuities of the lighting atmosphere noticed in the space. We will use a topological approach to space to see how topology can define architectural spatiality just by these discontinuity relationships.

\subsection{The Approach of Ambiances Between Typologies and Visualization}

The luminous ambiance is a critical subject nowadays because of its visible aspect. If the information comes from the different senses, our brain tends to decide for those that have a visible character (which comes to us from the eye); hence the absence of ambiguity in the luminous atmosphere.

J.R Pigeon [05] notes that it is only possible for man to visualize himself in his route if he becomes aware of his environment through his body. This awareness allows a better understanding of the architectural space. The first relationships between man and the route refer to visual capacities; man tends to understand the environment in which he finds himself and appropriate it through the decoding of information that space sends him.

Research on visualization of ambiances has been strongly developed; visualization converts information into images that can be used to explore and analyze. It is on the basis of human perception that we can build guidelines that make visualization very effective. The objective of the visualization was to improve teaching and learning procedures. [06] 
What is to be noted is that despite the very high number of visualization software, they are not available to designers, and most have been tested by academics. Software simulation helps to create a modelling very close to reality, which would allow a visualization of the atmosphere or ambiances. This visualization supports the physical environment of the ambiance, but also makes the user an important element of the spatial reading. [07]

\subsection{Topology and the Act of Displacement}

Although it is old in architecture, topology appeared in the field of architecture as a response to an urban problem of the last century [08], then many works of classification of architectural buildings [09].

The birth of the topological trend in contemporary architectural thought has led to the emergence of two currents: i) The first one is that of deconstructivist architects; who wanted to express the differences and heterogeneity of the physical and cultural contexts of our age through formal discontinuity strategies, ii) The second one is that of architects of the new avant-garde who seek to create a link between architecture and mathematics; Through the topological theories inspired by mathematics.

No theory specific to topological architecture has yet been formulated. Nevertheless, we could talk about a topological trend that architects, both theorists and operational architects, i) talk about or ii) adapt to design their projects with pure reference to mathematics. [10]

In the light of what G. Di Cristina had presented as a definition, we were able to conclude that topology is defined as the act of displacement according to a temporal duration. The dynamic movement of the body crosses time creating points, successively, throughout a route (duration). This point once created becomes an event. [11,12] It is therefore considered that it is possible to define topology, from an etymological point of view, as a transformation into continuity.

\subsection{The Luminous Ambiance in the Museum Route}

Maria Saraiva mentions in her work two types of ambients found in the museum : i) the first one is objectal and aims to enhance the value of the exhibited object and it is the oldest[13] and highlights the relationship between visitor/object, ii) the second one is functional which is based in addition to the relationships between visitor/exhibited object, the route that enters the visitor's perceptive experience and becomes the basis for the visitor's sensory experience. [14]

The museum route is the fundamental unit of museum design and its success. The route is defined according to the dictionary [15] LAROUSSE (2009, p. 356): "the route or path followed to go from one point to another". Common sense shows the complexity of this term.

In the case of museums, we refer to the solutions to the principles of circulation that have been developed according to their form [16] (Mariani. R, 2000): i) The "linear" route: an obligatory scheme, ii) The "labyrinth" route: no traffic restrictions, iii) The "centred" route: The public has the freedom to choose the route of their visit.

For some researchers, the route represents the movement of the body, the movement in space. For others, it is described as a design-visit interaction. With the route, the simple act of moving begins to make sense. The lighting ambiance in the museum route is essential for 
the success of the exhibition. The architectural aesthetics of the route and the degree of visitor satisfaction depend on the daylight.

If we carry out an analysis of the interpretation of architectural space in the visual field, we will realize that the details of the space (working levels, floors and ceilings...) do not seem dominant, but the image of the room is often determined by the surrounding surfaces. This image is defined by the distribution of light and dark and is none other than the spatial deformation through light, which will influence the atmosphere and well-being. [17]

\section{Materials and Method}

Depending on the definition of topology cited in the section "Topology and the Act of Displacement" and projected into the spatial components and their ambient characteristics, we will conclude that from the environmental point of view the part of space in which the human body moves (duration) is none other than the route, or the dynamic movement of the body (displacement) creates throughout this route intersection points that we will call "sequences" that are considered purely light events. [18] In this section, we will explain the methodology adopted to verify this definition.

\subsection{The Methodology}

\subsubsection{Sequential Analysis}

In fact, it is a question of listing the cascade of parameters required to highlight the analysis model [19], which we summarize as follows:

- Step 01. Identification of the route: it is a question of observing the route of the visit route in the museum plans, according to the description accompanying the graphic documents. This route will be drawn by means of the drawing on the plans on a blue layer.

- Step 02. Identification of the bays by their axes: it is a question of identifying the bays which give on to the route, and on another layer draw the axes of the lateral bays and the bays in a discontinuous line of red color.

- Step 03. Delimitation of the sequences of the route: the limits of the sequences are at mid-distance between the axes of two consecutive bays. And here we return to the definition of the sequence that we have developed from the exploration of a literature review; the sequence is defined as the portion of the architectural space that is part of a route. A portion that is identified by the axis of a bay operated in the wall and whose boundaries are at the vicinity of the axes, the same route, located halfway between the bay of the sequence in question.

- Step 04. Description of the sequences: by establishing a table called the descriptor containing a description of all the variables of the bay and the conformation.

This sequential analysis model allowed us to highlight the light sequences and their characteristics as a function of the bay variables analysed. The qualifiers were chosen according to the rules of the European Handbook Of Daylight, which we quote here: i) - the type of lighting, ii) - the orientation, iii) - the position, iv) - the inclination) - the shape, vi) the size, vii) - the glazing, viii) - the additional glazing. These variables are those that influence the lighting ambiance within a sequence of the studied route [20] 
Then, according to the conformation, we noted our observations on the changes in conformation that are due to the presence of discontinuities according to the variables: i) materials, ii) -colour, iii) -texture, iv) -morphology.

Once defined, the sequences can be analysed in several ways, namely:

- Statistical analysis: using STATESTICA 7 software to find: i) correspondences between the resulting discontinuities, ii) correspondences between the discontinuities and the design elements related to light.

- Simulation: through the ECOTECT 05 software for 3D modelling, and RADIANCE for surface illuminance and luminance, its role is to: i) confirm and visualize the discontinuities that exist in the museum route, ii) make a quantitative comparison between the results.

\subsection{The Corpus of Study}

\subsubsection{The Selection Criteria and the Corpus of Study}

To verify this hypothesis, we have chosen to work on permanent exhibition spaces in museums because the luminous ambiance is considered as a totalitarian ambiance, and permanent exhibition spaces provide a function that does not change over time. We chose six museums designed during the same historical period (from 1980 onwards and located in the European context), whose architects intended to work with natural light from the design stage, and on which we collected data going as far as describing the ambiances created by architects and journalists (In addition to photos, graphic files...).

Based on the definition of mathematical topology in architecture, we have classified our museums according to their architectural forms into two categories: i) a first where the volume is characterized by an absence of deformation or formal discontinuity, which includes three types of museums (the Departmental Museum of Prehistory, the Beyeler Riehen Museum, and the Acropolis Museum of Athens), ii) and a second where the formal deformations exist in the volume. This category also includes three museums (the Guggenheim Museum Bilbao, the Jewish Museum of Berlin, the Hergé Museum).

This choice of volume is also linked to the nature of the route, where we notice that for museums where there are no volumetric deformations (simple volume), the routes are unambiguous and symmetrical in most cases. In the case of museums with distorted volume distorted the route and mixed, or labyrinthine nature. 


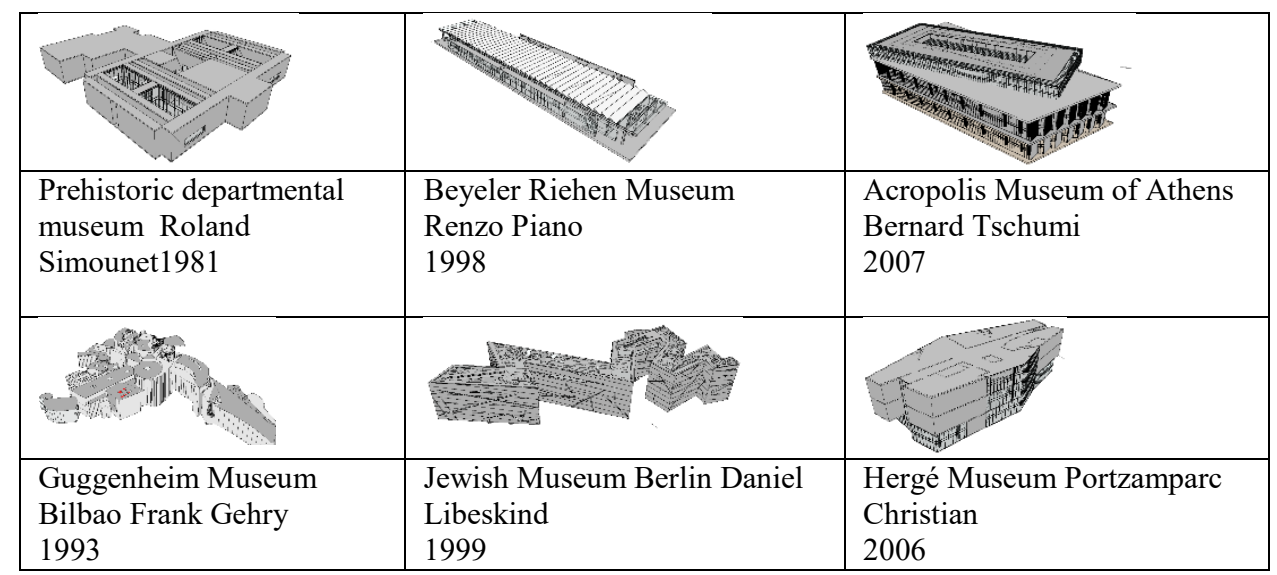

Table 01 : Presentation of the Volumes Made by Ecotect of the Case Studies

\section{Results and Discussions}

\subsection{The Analysis of the Correspondences Between the Discontinuities Resulting from the Sequential Analysis}

\subsubsection{The Sequences}

There is no precise typology to define the sequences, the nature of the volumetry, and the interior spaces or even the route. The existed sequences are very varied in nature. We have summarized the results of the sequential analysis in the following table where we find the number of typological variations and number of sequences, and finally the resulting discontinuities equal to or greater than $50 \%$ in all the study cases. 


\begin{tabular}{|c|c|c|c|c|}
\hline $\begin{array}{l}\text { The } \\
\text { architectural } \\
\text { form }\end{array}$ & The case study & $\begin{array}{l}\mathrm{N}^{\circ} \\
\text { Typological } \\
\text { variation of } \\
\text { sequence }\end{array}$ & $\begin{array}{l}\text { Total of } \\
\text { sequences }\end{array}$ & Variable of discontinuity \\
\hline \multirow[t]{3}{*}{$\begin{array}{l}\text { without } \\
\text { deformation }\end{array}$} & $\begin{array}{l}\text { Prehistoric } \\
\text { departmental } \\
\text { museum }\end{array}$ & 04 & 10 & - $\quad$ Orientation \\
\hline & $\begin{array}{l}\text { Beyeler Riehen } \\
\text { Museum Renzo }\end{array}$ & 04 & 19 & $\begin{array}{ll}- & \text { Type of lighting } \\
\text { - } & \text { Orientation }\end{array}$ \\
\hline & $\begin{array}{l}\text { Acropolis } \\
\text { Museum of } \\
\text { Athens }\end{array}$ & 09 & 80 & $\begin{array}{lc}- & \text { Type of lighting } \\
- & \text { Glazing } \\
\text { complements } \\
\text { - } \quad \text { Orientation } \\
\end{array}$ \\
\hline \multirow[t]{3}{*}{$\begin{array}{l}\text { With } \\
\text { deformation }\end{array}$} & $\begin{array}{l}\text { Jewish Museum } \\
\text { Berlin }\end{array}$ & 05 & 53 & $\begin{array}{ll} & \text { Type of lighting } \\
- & \text { the size of the bay } \\
\text { - } & \text { orientation } \\
\text { - } & \text { bay position }\end{array}$ \\
\hline & $\begin{array}{l}\text { Guggenheim } \\
\text { Museum Bilbao }\end{array}$ & 09 & 31 & $\begin{array}{ll}\text { - } & \text { Type of lighting } \\
\text { - } & \text { wall inclination } \\
\text { - } & \text { shape of the bay }\end{array}$ \\
\hline & Hergé Museum & 15 & 15 & $\begin{array}{ll}- & \text { Type of lighting } \\
\text { - } & \text { the size of the bay } \\
\text { - } & \text { orientation } \\
\text { - } & \text { wall inclination }\end{array}$ \\
\hline
\end{tabular}

Table 02: Summary of the Results of the Sequential Analysis.

\subsubsection{The correspondences between the discontinuities of the sequences and their visualizations}

In this section, we will present the results of the sequential analysis, accompanied by some simulation to confirm the existence of the discontinuities. For the simulations, we selected the highest attendance periods and hours for each case study. We first performed our simulations by lighting curve, the curves are sometimes of a visible nature as in the case of the Hergé Museum. But in other cases, they are not and do not allow a good reading of the results.

What interests us in the simulation is not the results compared to the standards, but just the visualization that would highlight the discontinuities. To do this, we present the results as a synthetic image with some surface illumination values.
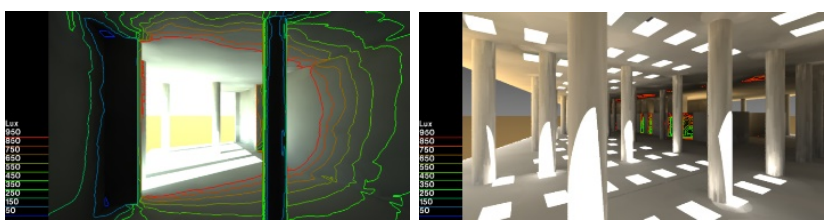

Fig. 01: results of the simulation by lighting curve for the case of the Herge Museum and the Acropolis Museum. 


\subsubsection{Case-by-case study}

a) For the cases of museums with undistorted volumes:

- $\quad$ The departmental museum of prehistory

Based on the analysis, it was found that there is no variation in the characteristics of the space in all sequences such as wall inclination.

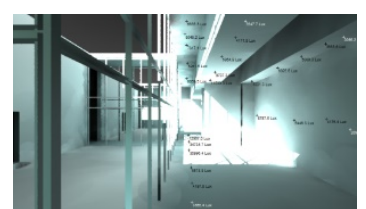

21 March

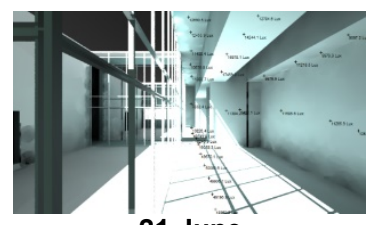

21 June

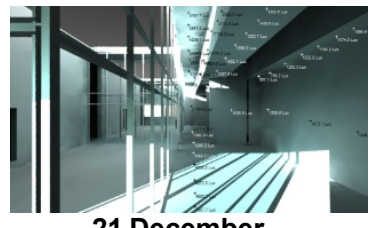

21 December

Fig. 02: route visualized by radiance for one hour of high attendance at the departmental museum of prehistory.

There is a dominance of lateral lighting in the sequences (64\%), logically distributed over the four orientations: i) a high percentage for EAST and WEST (39\%), and ii) a low percentage for SOUTH and NORTH (11\%). According to the analysis, there is a predominance of medium-sized side bays, followed by medium-sized zenithal bays, and large side bays.

\section{- $\quad$ The Beyler Reihn Museum}

It should be noted that the ceiling is completely open to the sky, consisting of zenithal bays. Space in all sequences retains these spatial characteristics. No inclination concerning the walls. We have visualized parts of the route showing this spatial stability for the time when the number of visitors is at its maximum at $2 \mathrm{pm}$.

The museum is dominated by zenithal lighting in all sequences (61\%). The zenithal bays occupy almost $(100 \%)$ of the total ceiling surface, the lateral lighting is (39\%), mainly EAST oriented (58\%), NORTH oriented (25\%), and SOUTH oriented at $17 \%$. All the museum's bays are large.

The horizontal windows are protected by removable skylights that instantly regulate and manage the amount of natural light inside the museum. For side bays and whatever their orientation (SOUTH or NORTH), they are protected by a horizontal projection that the architect has designed as a decorative element.

- The Acropolis Museum of Athens

The space retains its characteristics for all sequences, with no inclination in the walls. All textures are smooth. The visualization allows us to see this spatial stability for part of the course, for the time when attendance is very important. 


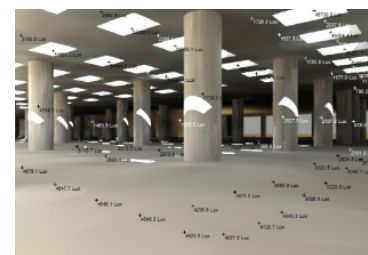

21 March

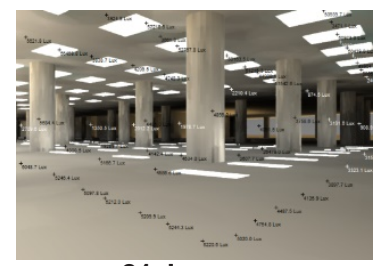

21 June

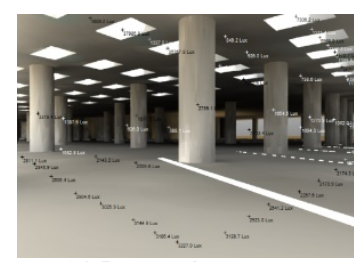

21 December

Fig. 03: route visualized by radiance for one hour of high attendance at the Acropolis Museum in Athens.

It can be seen that the dominant type of lighting in the museum is lateral. It is divided into several orientations: i) WEST (25\%), ii) EAST (23\%), iii) NORTH-(19\%), iv) SOUTHWEST (13\%), v) NORTH and SOUTH (10\%). Zenithal lighting represents $10 \%$ of all types of lighting.

The visualization of the lighting ambiance in the part of the linear route allowed us to draw the curve of the variation of the surface illumination variation, The graph represents a part of the route, where we can see that the surface illumination curves cross from one sequence to another and vary between 400 and 1900lux for the West orientation at 3pm, the curves are in an increasing order, this is due to the linear character of the route (time or attendance and very high in summer period).

b) In the case of museums with deformed volumes

\section{- Jewish Museum, Berlin}

There is no variation in the characteristics of the space. No wall inclination is observed. According to the analysis, it was found that the dominant type of lighting is zenithal $(59 \%)$, followed by side lighting (45\%). The latter is divided into several orientations: i) SOUTHEAST (31\%), ii) NORTH (23\%), iii) SOUTH-WEST (31\%), iv) EAST and NORTHEAST $(12 \%)$, and finally v) WEST (8\%).

The bi-varied analysis reveals that there is no dominance in terms of lighting type and bay size, but in terms of bay position and size, the middle bay in the middle of the wall is the most dominant for this case study.
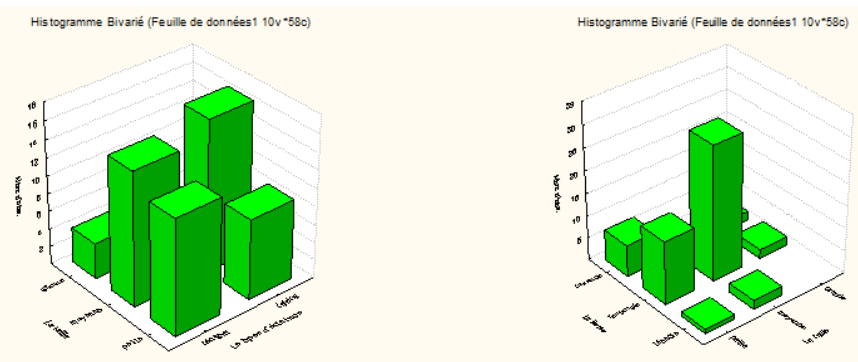

Fig. 04: Correspondence size - type of lighting and Correspondence Size - Position (Jewish Museum Berlin) 
In the graph, the curves are all variable, which confirms the existence of discontinuity in the proportion of the bay to the wall in this part of the Jewish Museum in Berlin.

- Guggenheim Museum, Bilbao

We notice a discontinuity in the morphology of the walls, where the inclination of the walls in some parts of the route is done in a multidirectional way.

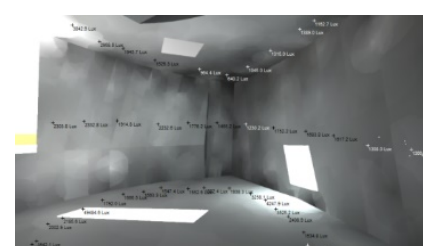

21 March

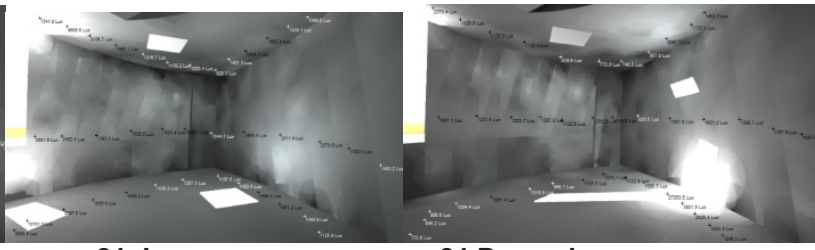

21 December

Fig.05: radiance visualized route for one hour of high attendance at the Guggenheim Museum in Bilbao.

The zenithal lighting constitutes $55 \%$ of the total lighting of the museum, we also find $45 \%$ of lateral lighting, several orientations with a dominance of the SOUTH orientation $38 \%$, the NORTH orientation bays constitute $31 \%$, that of the WEST orientation $15 \%$, then an equality between the SOUTH-WEST and NORTH-WEST orientation with a percentage of $8 \%$.

We also see a dominance of square bays for the medium size zenithal lighting type, followed by large rectangular side bays and a small number of large rectangular zenithal bays.

Histogramme Bivarié (Feuille de données1 10v*40c)

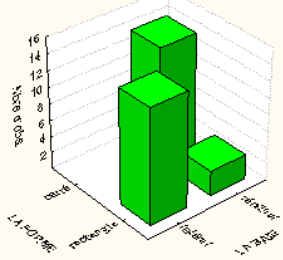

Histogramme Bivarié (Feuille de données1 10v*40c)

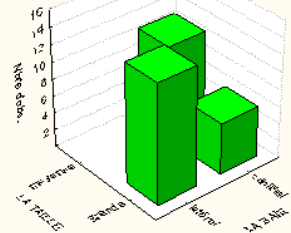

Fig.06: Correspondence Form-Type of lighting and Correspondence Size-Type of lighting (Guggenheim Museum Bilbao)

For the second graph, stability is present in sequence 03 and 04 . However, for the rest of the sequences, the lighting curves are variable, and this characterizes the discontinuities in the proportions of the bay in the case of the Bilbao Museum.

- $\quad$ The Hergé Museum

The space is characterized by a variation of the walls, i.e. an inclination composing the passage from one sequence to another. The inclination of the wall is inward in one sequence, in the second it is absent, and vice versa for the entire route. 
Side lighting is the majority $(76 \%)$. Side lighting varies in orientation: a dominance of the EAST orientation (38\%), equality between the SOUTH and NORTH orientation (23\%), and finally a minority for the WEST orientation (19\%).

It should also be noted that all the bays, regardless of their lighting types, are rectangular in shape and large in size overall.

\subsubsection{The types of discontinuities according to the route in the museums of the study corpus}

The sequential analysis has allowed us to identify the discontinuities that can characterize the lighting ambiance in our museums, the multivariate analysis between the different variables of the discontinuities to reveal correspondences between them. We summarize them as follows:

- For museums with a linear route, we have noticed the existence of three types of discontinuities: those of the proportion of the bay, those of its position, and its size.

- For museums with mixed or labyrinthine routes, we have noticed the existence of discontinuity in the complement of glazing, the shape of the bay, its orientation, and the type of lighting.

\section{Conclusion}

This research has allowed us to bring out in our museums a very varied range of sequence typology, each sequence is different from the other, thanks to the variables defined above that characterize it.

The corpus museums are formally varied, whether in terms of the volume of the building or the shape of the project's interior spaces, and depending on the characteristics of the route and its shape, we found that museums whose route is labyrinthine or mixed belong generally to museums whose volume is characterized by the existing deformation. On the other hand, museums with a linear or centred route are museums of the modern style or the new avantgarde, which is characterized by the absence of volumetric deformation of the project. And finally, thanks to the sequential analysis we were able to deduce that for each type of route, corresponds to a precise type of discontinuity.

The role of simulation in this research is to reproduce conditions of the exhibition spaces so that an accurate assessment and reading of the spatial characteristics as a whole and of the variations in illumination in the different sequences of the same route can be assessed through the different spatial visualizations.

This research has allowed us to confirm our hypothesis that light topology is defined as the discontinuities in the light sequences which characterize architectural space. The route in this research is composed of a sequence that can be defined as a succession of purely luminous events, where one passes from one sequence to another through a transition. This transition can be distinguished by the change of the lighting ambiance within the same space.

Topology can, through the relationship between sequences, create a new spatiality of architectural space other than geometric space. It will have a very important role if we treat each sequence separately in museums in order to improve the conditions for future exhibitions. The results can also contribute to the optimization of light comfort in exhibition spaces. 


\section{References}

1. P. Von Meiss, De la forme au lieu, une introduction à l'espace architectural, (EDP polytechniques et universitaires romandes, Lausanne. 1993)

2. B. Zevi, Apprendre à voir l'architecture (1993)

3. J. Cousin, L'Espace Vivant. Introduction à l'Espace ( Ed. Le Moniteur, Paris. 1980).

4. G. Bonnet, Rayons sonores et ondes de lumière ?cul,sciec,phys (2005)

5. J.R. Pigeon, Essai (projet) soumis en vue de l'obtention du grade M.Arch. École d'architecture Université Laval (2013)

6. A. D' Alba, Analyzing Visitors' Discourse, Attitudes, Perceptions, and Knowledge Acquisition in an Art Museum Tour After Using a 3D Virtual Environment, doctorat thesis, university of north Texas. (2012)

7. D.Siret, P. Woloszyn, Ambiances architecturales et urbaines - Du complexe au simplexe, Les cahiers de la recherche architecturale 42/13 - Ambiances architecturales et urbaines (ED Luc Adolphe Parenthèses, Paris, 1998)

8. M.P.Corcuff, Penser l'espace et les formes, Thèse de doctorat en géographie, le 26 novembre à l'Université de Rennes 2(2007)

9. M. H. Ibrahim,A, J King Saud Univ.,9, Arch. \&Planning, 1-30. (1997)

10. G .Di Cristina, Architecture and science 6-13, (EDB wiley academy,Great Britain, 2001

11. S.Saraoui, A.Belakehal, Actes de la conférence BASC, 156 (2011)

12. S.Saraoui, A.Belakehal, A.Attar, A.Bennadji, ZEMCH 2018, Melbourne, Australie, 92-94 (2018)

13. M. Saraiva, L'environnement sensible dans les musées à caractère ethnologique Thèse de doctorat encadré par : J.F. Augoyard. (2001)

14. S.Saraoui, A.Belakehal, A.Attar, A.Bennadji, ZEMCH 2018, Melbourne, Australie, 97 (2018)

15. Dictionary Le Petit Larousse 2009, p. 356 (2009)

16. S. Mariani-Roussset, L'espace urbain en méthode, 29-85 (1996)

17. S.Garry The reasoning architect mathematics and science in design, (EDB MC Graw Hill international ,edition Singapore,1990)

18. A.Sossinsky, Noeuds Genèse d'une théorie mathématique, (EDB Seuil, Paris, 1999)

19. S.Saraoui, A.Belakehal, Actes de la conférence BASC, 159 (2011) 